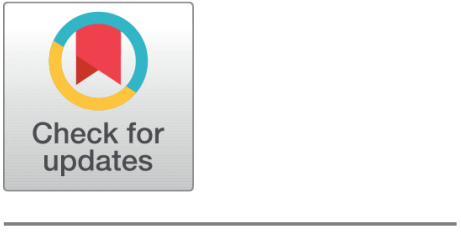

open ACCESS

Received: 05.01.2021

Accepted: 27.02.2021

Published: 22.03 .2021

Citation: Al-Ashhab MS, Nabil OM, Afia NH (2021) Perishable products supply chain network design with sustainability. Indian Journal of Science and Technology 14(9): 787-800. https://doi.org/ 10.17485/IJST/v14i9.24

* Corresponding author.

omnianabil@gmail.com

Funding: None

Competing Interests: None

Copyright: (c) $2021 \mathrm{Al}$-Ashhab et al. This is an open access article distributed under the terms of the Creative Commons Attribution License, which permits unrestricted use, distribution, and reproduction in any medium, provided the original author and source are credited.

Published By Indian Society for Education and Environment (iSee)

ISSN

Print: 0974-6846

Electronic: 0974-5645

\section{Perishable products supply chain network design with sustainability}

\author{
M S Al-Ashhab ${ }^{1,2}$, Omnia M Nabili,3*, Nahid H Afia ${ }^{1}$ \\ 1 Design \& Production Engineering Dept., Faculty of Engineering, Ain-Shams University, Cairo, \\ Egypt \\ 2 Dept. of Mechanical Engineering, College of Engineering and Islamic architecture, Umm \\ Al-Qura University, Makkah, Saudi Arabia \\ 3 Dept. of Industrial Automation, German University in Cairo, Egypt
}

\section{Abstract}

Background/Objectives: This study addresses the problem of sustainable supply chain network design for perishable products. Perishable products lose their value or deteriorate in a limited time, from the moment they are produced. Methods/Statistical analysis: A mathematical model is developed to design sustainable, single product, multi period, three-echelon supply network including manufacturer, warehouse, and retailer. The problem is formulated as mixed-integer nonlinear programming. Besides, the model is solved by non-linear Generalized Reduced Gradient solver in Excel. Findings: The behaviour of the model has been verified through solving several scenarios. The effect of demand on system behaviour has been studied. Novelty/Applications: The model considered inventory of perishable products in multi-periods. In addition, it adopts the concept of preventing the expiration of the perishable products, to minimize the environmental impact in addition to maximizing the profit to assure sustainability of the supply chain. The model is solved by non-linear Generalized Reduced Gradient solver in Excel. The proposed model considerably assists the supply chain organizations to design their network more efficiently.

Keywords: Sustainability; Supply chain network design; perishable products; MINLP; Inventory; FIFO; expiration; Generalized Reduced Gradient solver

\section{Introduction}

There is a great importance to study the perishable product supply chain network design. Perishability is mostly considered in food and healthcare industry where the products easily deteriorate during manufacturing, storage, and distribution. Perishable products lose their value in a certain time, from the moment they are produced. Companies should manage those products subjected to perishability. Inventory management of perishable is complex because of retailers' demand variability, distribution, and lifetime. Food, dairy products, pharmaceutical products, and blood are main examples for perishable products. The limitation of the shelf life, overproduction, and storage are the main features of perishable products. 
Perishable products will have a significant effect on the environment. So, there is a need to incorporate the study of sustainability with the perishable supply chain network design. Generally, sustainability addresses the incorporation of the three pillars including environmental, economic, and social aspects. The goal behind the Sustainable Supply Chain Network Design (SSCND) is to balance between the different objectives of minimizing both environmental and social impacts and maximizing economic performance.

Recently approaches consider perishable products, so they should manage the perishability of those products by considering the availability of inventory and demand variability, the lifetime of products and when it became invalid. Moreover, sustainability must be taken into consideration dealing with the problem as multi objectives to balance between economic, environmental, and social objectives. Perishable products have a limited lifetime; therefore, storing products in warehouse should be continuously monitored in order to avoid waste and reaching expiration. This will have a significant impact on the environment.

\section{Literature Review}

There are some research papers addressing the SSCND for perishable products as presented in Table 1.

The classification of the research papers addressing SSCND for perishable products is shown in Appendix A. Papers are classified according to objective functions, model types, solution approaches, software tools used and the field of application.

The approaches to solve SSCND were either exact or heuristics and Meta heuristics. Models were developed as linear, nonlinear, mixed integer linear programming and Mixed Integer Non-Linear Programming (MINLP). Others used Genetic algorithm $(\mathrm{GA})^{(1-5)}$, Particle Swarm Optimization (PSO) ${ }^{(1)}$ and Simulated Annealing (SA) $)^{(6,7)}$ and meta-heuristic algorithms based on Pareto solutions ${ }^{(3,8)}$. Eskandarprour et al. ${ }^{(9)}$ reviewed the methods used for models of multi-objective as weighted sum of objectives method, epsilon-constraint method, metaheuristics and Multi Criteria Decision Analysis (MCDA). Some researchers adopted multi-objective solution approaches in their model. Some of them developed solution approaches based on augmented-constraint method to solve their models ${ }^{(10-13)}$. Other researchers applied $\varepsilon$-constraint method for their model ${ }^{(14,15)}$. Some researchers developed a solution approach based on both Lagrangian relaxation and $\varepsilon$-constraint to solve their model ${ }^{(16)}$. Also, the methods of the weighted sum method and the goal programming method have been used in some models ${ }^{(17,18)}$.

Regarding the objective functions used in the different research papers, it has been shown that some researchers addressed models with single-objective functions, others addressed models with two or more objective functions. Some papers addressed the three pillars of sustainability in designing their supply chain structure. Their proposed model aims to minimize the total cost, minimize the total amount of Carbon Dioxide $\left(\mathrm{CO}_{2}\right)$ emission and also maximize the social effect. Traditional Supply Chain Network Design (SCND) addressed single-objective models that aimed at maximizing the economic performance. They developed models of a single objective function considering the economic aspect of sustainability ${ }^{(1,19-22)}$. Due to the increased focus on the environmental impact, some researchers addressed the environmental aspect along with the traditional economic one. They developed bi-objective models considering both the economic and environmental objective functions ${ }^{(4,6,14,23-25)}$. Their proposed models aim to minimize the environmental impacts through minimizing $\mathrm{CO}_{2}$ emissions. The third pillar of sustainability, which is the social aspect, aims to maximize the social influence, which includes the created number of job opportunities and the number of unemployed workers at the manufacturers. Some researchers considered all the three pillars of sustainability i.e., economic, environmental, and social ${ }^{(7,8,11,12,26)}$. They developed multi-objective models with economic, environmental and social objective functions.

Other objective functions have been considered such as: maximizing the capacity utilization of facilities ${ }^{(10)}$, minimizing the expected products' delivery time from/to different facilities ${ }^{(15,16,18)}$, maximizing the efficiency of the considered supplier ${ }^{(27)}$, considering product freshness, product quality, maximizing satisfaction in aid of the usage of technology ${ }^{(28)}$, minimizing the maximum unsatisfied demand of products ${ }^{(29,30)}$, maximizing the total purchase probability of the all retailer zones ${ }^{(31)}$, minimizing demand unresponsiveness ${ }^{(3)}$.

The applications of perishable products may include food, beverages, dairy products, pharmaceutical products and even blood. Some researchers validated their perishable supply chain model in a real case study in companies for beverages and dairy products ${ }^{(32,33)}$. Other researchers considered the distribution of ready-made foods of meat products to distribution centres and applied their model on a real meat $\mathrm{SCND}^{(10,28)}$. On the other hand, some researchers applied their proposed model on the pharmaceutics industry.

The literature review revealed the following findings:

- Few researchers considered inventory in designing their supply chain network.

- Some researches dealt with perishable products and the First-in First-Out (FIFO) inventory policy, but without considering sustainability. 
- Some researches considered sustainability, but for generic products, not perishable products.

- Some researches considered the expiration costs, but didn't adopt the concept of preventing the expiration of products, and subsequently minimizing the environmental impact.

This study addresses the problem of sustainable supply chain network design for perishable products. A mathematical model is developed to design sustainable multi period, three echelon supply network including manufacturer, warehouse, and retailer. The problem is formulated using MINLP.

The model has been solved by non-linear Generalized Reduced Gradient (GRG) solver in Microsoft Office Excel. All computational experiments have been performed on a laptop with core (TM) i7 $1.8 \mathrm{GHz}$ and $16 \mathrm{~GB}$ of RAM.

The aim of the model is to find the best configuration of a supply chain and to decide the quantity of units to be produced at each period, without extra needless production, and the quantities of units to be transferred from manufacturer to warehouse, and from warehouse to retailer. This decision relies on the perishability of products, the demand of the retailers, and handling inventory according to the different ages of products in the warehouse. FIFO inventory policy is adopted by most of the producers in the field of perishable products. It is favoured in the real-life industry as it avoids waste and expiration of products.

Table 1. Reviewed papers on SSCND for perishable products

\begin{tabular}{|c|c|c|c|c|}
\hline No. & Paper & \multicolumn{2}{|c|}{ Objective functions } & Application \\
\hline 1 & Dwivedi et al. ${ }^{(5)}$ & Single & Eco-Env & agro-food \\
\hline 2 & Jiang et al. ${ }^{(32)}$ & $\mathrm{Bi}$ & Eco-Env & beverage \\
\hline 3 & Rohmer et al. ${ }^{(14)}$ & $\mathrm{Bi}$ & Eco-Env & food \\
\hline 4 & Yakavenka et al. ${ }^{(18)}$ & Multi & Eco-Env-Other & fruit \\
\hline 5 & Eskandari-Khanghahi et al. ${ }^{(7)}$ & Multi & Eco-Env-Soc & blood \\
\hline 6 & Halim et al. ${ }^{(24)}$ & $\mathrm{Bi}$ & Eco-Env & pharmaceutical \\
\hline 7 & Patidar et al. ${ }^{(1)}$ & Single & Eco & agri-food \\
\hline 8 & Tavakkoli-Moghaddam et al. ${ }^{(28)}$ & Multi & Eco-Env-Other & meat \\
\hline 9 & Musavi and Bozorgi-Amiri ${ }^{(31)}$ & Multi & Eco-Env-Other & food \\
\hline 10 & Varsei and Polyakovskiy ${ }^{(11)}$ & Multi & Eco-Env-Soc & wine \\
\hline 11 & Zahiri et al. ${ }^{(8)}$ & Multi & Eco-Env-Soc-Other & pharmaceutical \\
\hline 12 & Hasani, A., Zegordi et al ${ }^{(19)}$ & Single & Eco & deteriorating inventory \\
\hline 13 & Pauls-Wormet al ${ }^{(4)}$ & $\mathrm{Bi}$ & Eco-Env & food \\
\hline
\end{tabular}

\section{The Developed Mathematical Model}

\subsection{Model description}

The design of multi-period, three-echelon perishable supply chain is considered. It consists of manufacturers, warehouse, and retailers. Products are assumed to have a known shelf-lifetime after which they will be expired and disposed. The main concern of this study is to optimally find the candidate locations of the manufactures, and to specify the decisions of the quantities of units transferred from the manufacturers to the warehouse. Consequently, the quantities that are transferred from the warehouse to the retailers can be also determined. The quantities entering the inventory that exists in the warehouse in different periods are required to be determined at the end of each period along with the objective of maximizing the expected profit. Figure 1 demonstrates the general structure of the supply chain. Figure 2 shows the relation between the different facilities in the model. 


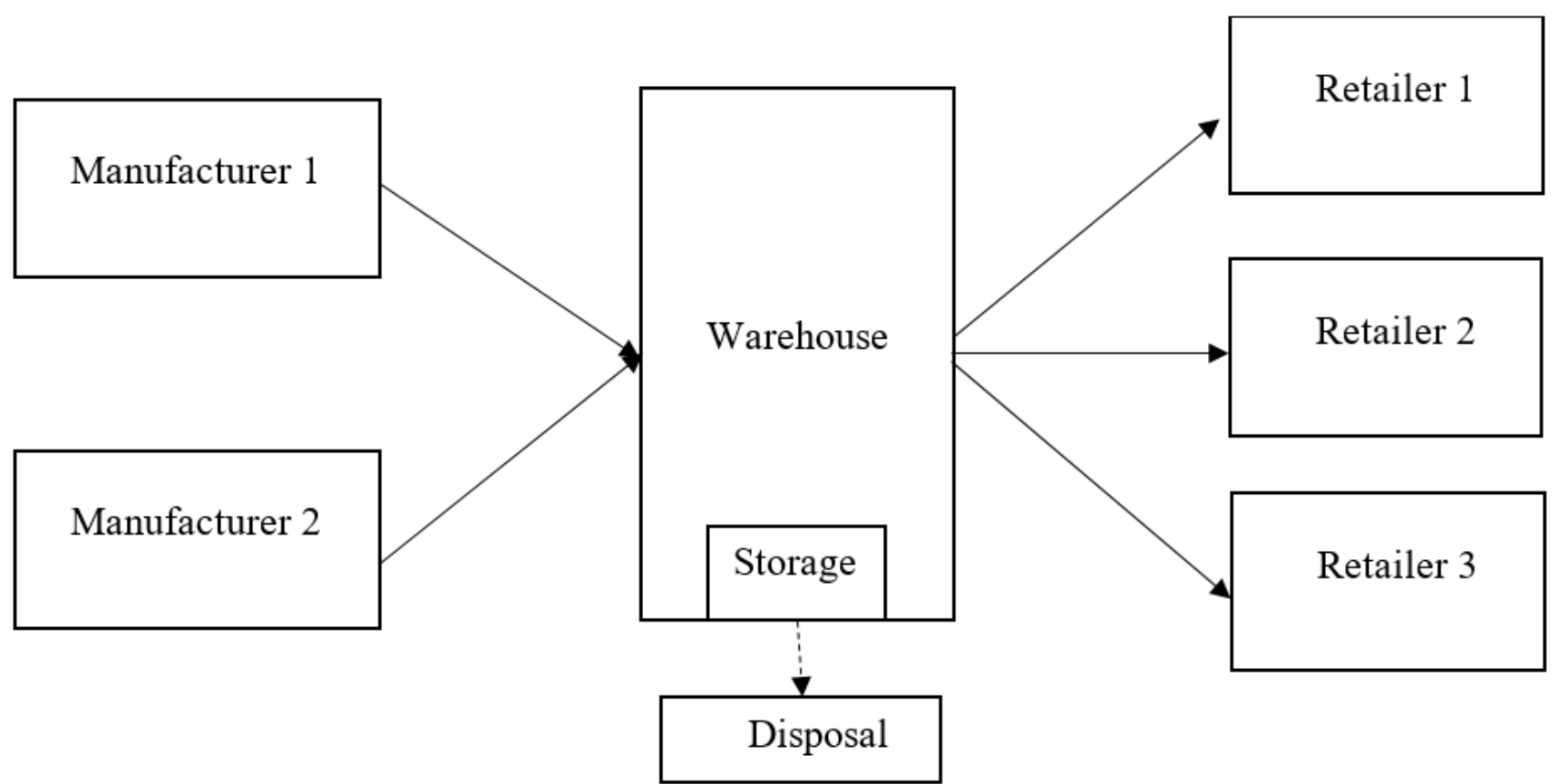

Fig 1. General structure of the proposed supply chain

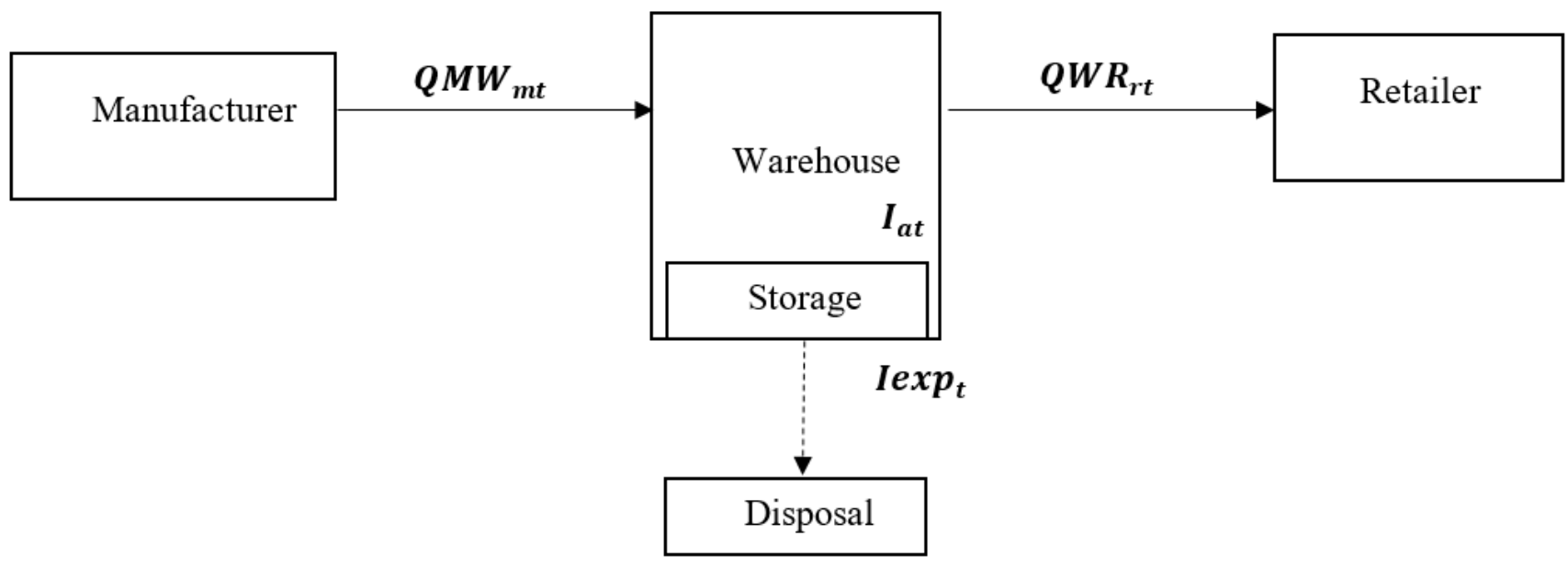

Fig 2. Model flow diagram

\subsection{Model assumptions}

The mathematical model is developed based on the following assumptions:

- Retailer's demand is known and deterministic.

- Inventory is held at the warehouse.

- The shelf-lifetime of products is limited.

- Backlog is considered.

- FIFO inventory management is used, in which the first produced items are issued first.

- Products are considered as waste, when they reach their shelf-lifetime; and subsequently disposed out of the warehouse inventory. 
- Capacities of manufacturers and warehouse are predetermined.

\subsection{Mathematical model formulation}

\section{Notations}

\begin{tabular}{ll}
\hline Sets & \\
\hline$T$ & Set of planning periods \\
$a$ & Set of ages of products \\
$M$ & Set of potential locations of manufactures \\
$R$ & Set of retailers \\
\hline Parameters & \\
\hline $\mathrm{S}$ & Shelf-lifetime of product \\
$D_{r t}$ & Demand of retailer (r) in period ( $\mathrm{t})$ \\
$C a p M_{m t}$ & Capacity of manufacturer $(\mathrm{m})$ in period (t) \\
$C a p W_{t}$ & Capacity of warehouse in period (t) \\
$p r$ & Price per unit \\
$T C$ & Transportation cost per unit per distance \\
$D M W_{m}$ & Distance between manufacturer (m) and warehouse \\
$D W R_{r}$ & Distance between warehouse and retailer $(\mathrm{r})$ \\
$I H C$ & Inventory holding cost per unit per period \\
$E C$ & Expired cost per unit \\
$S C$ & Shortage cost per unit \\
$M C$ & Material cost per unit \\
$P C$ & Production cost per unit \\
$F C$ & Fixed cost \\
\hline Variables & \\
\hline$Q M W_{m t}$ & Quantity of units transferred from manufacturer (m) to warehouse in period (t) \\
$Q W R_{r t}$ & Quantity of units transferred from warehouse to retailer (r) in period (t) \\
$I_{a t}$ & Inventory of age (a) at the end of period (t) \\
$I e x p_{t}$ & Expired inventory at the end of period (t) \\
$X_{m}$ & Binary variable, equals 1 if manufacturer (m) is established; 0 otherwise \\
$Z$ & Total profit \\
\hline &
\end{tabular}

- The ages of products are indexed by $a=1, \ldots, S$; where $S$ is the shelf lifetime.

- $\mathrm{I}_{a t}$ indicates the inventory of age (a) at the end of period ( $\mathrm{t}$ ).

- $\mathrm{I}_{1 t}$ indicates inventory of age $(\mathrm{a}=1)$ at the end of period $(\mathrm{t})$.

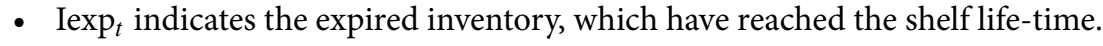

The proposed model is formulated as follows:

\subsubsection{Objective function}

The economic objective function shown in equation (1) aims to maximize the profit of the supply chain network.

$$
\text { Profit }=\text { Sales Income }- \text { Total costs }
$$

Total costs include:

- Fixed cost

- Production cost

- Material cost 
- Transportation cost

- Inventory holding cost

- Expiration cost

- Shortage cost

The objective function of the proposed model is as follows:

$$
\begin{aligned}
\max Z= & \sum_{r \in R} \sum_{t \in T} Q W R_{r t} p r \\
& -\sum_{m \in M} F C X_{m} \quad-\sum_{m \in M} \sum_{t \in T} Q M W_{m t}(P C+M C) \\
& -\sum_{m \in M} \sum_{t \in T} Q M W_{m t} T C \quad D M W_{m} \\
& -\sum_{r \in R} \sum_{t \in T} Q W R_{r t} T C \quad D M W_{r}-\sum_{a \in S} \sum_{t \in T} I_{a t} I H C \\
& -\sum_{t \in T} \operatorname{Iexp}_{t} E C \quad-\sum_{r \in R} \sum_{t \in T} S C\left(\sum_{1}^{t} D_{r t}-\sum_{1}^{t} Q W R_{r t}\right)
\end{aligned}
$$

\section{Sales income}

$$
\text { Sales income }=\sum_{r} \sum_{t} Q W R_{r t} p r
$$

The sales income is equal to the quantity of units transferred from the warehouse to the retailers $(r)$ during all time periods ( $t)$ multiplied by the price per unit.

\section{Fixed establishment cost}

Fixed establishment cost of the manufacturers $=\sum_{m} F C X_{m}$

$$
X_{m}=\left\{\begin{array}{l}
1, \text { if a manufacturer }(m) \text { is established } \\
0, \text { Otherwise }
\end{array}\right.
$$

The fixed establishment cost of the manufacturers is calculated by multiplying the fixed cost per manufacturer $(\mathrm{m})$ by a binary decision variable $\mathrm{X}_{m}$ that equals 1 if a manufacturer is established in candidate location $(\mathrm{m})$; and 0 otherwise.

\section{Production cost}

$$
\text { Production cost }=\sum_{m \in M} \sum_{t \in T} Q M W_{m t} P C
$$

The production cost is calculated by multiplying the quantity of units transferred from the manufacturer to the warehouse by the production cost per unit.

\section{Material cost}

$$
\text { Material cost }=\sum_{m \in M} \sum_{t \in T} Q M W_{m t} \quad M C
$$

The material cost is calculated by multiplying the quantity of units transferred from the manufacturer to the warehouse by the material cost per unit.

\section{Transportation cost}

$$
\text { Transportation cost }=\sum_{m \in M} \sum_{t \in T} \quad Q M W_{m t} T C \quad D M W_{m}+\sum_{r \in R} \sum_{t \in T} Q W R_{r t} T C D W R_{r}
$$

The transportation cost is calculated by multiplying the quantity of units transferred from the facilities by the transportation cost per unit per unit distance and by the distance between the facilities. 


\section{Inventory holding cost}

$$
\text { Inventory holding cost }=\sum_{a \in S} \sum_{t \in T} I_{a t} I H C
$$

The inventory holding cost is calculated by multiplying the inventory entering in all periods at the end of all periods by the unit inventory holding cost.

\section{Expiration cost}

$$
\text { Expiration cost }=\sum_{t \in T} \quad \operatorname{Iexp}_{t} \quad E C
$$

The expiration cost is calculated by multiplying the expired inventory at the end of all periods by the unit expiration cost.

\section{Shortage cost}

$$
\text { Shortage cost }=\sum_{r \in R} \sum_{t \in T} S C \quad\left(\sum_{1}^{t} D_{r t}-\sum_{1}^{t} Q W R_{r t}\right)
$$

The shortage cost is calculated by the difference between the cumulative demand of all retailers till each period and the cumulative quantity transferred from warehouse to retailers (satisfied demand till each period multiplied by the unit shortage cost per period.

\subsubsection{Constraints}

This section presents the constraints of the proposed model.

\section{Manufacturer capacity constraint}

$$
Q M W_{m t} \leq \operatorname{CapM}_{m t} X_{m}, \quad \forall m, t
$$

Constraint (10) guarantees that the quantity of units transferred from manufacturer $(\mathrm{m})$ to warehouse cannot exceed the manufacturer pre-specified capacity.

\section{Warehouse capacity constraints}

$$
\begin{gathered}
\sum_{m \in M} Q M W_{m 1} \leq \operatorname{CapW}_{1} \\
\sum_{m \in M} Q M W_{m t}+\sum_{a=1}^{S} I_{a, t-1} \leq \operatorname{CapW}_{t}, t>1
\end{gathered}
$$

Constraint (11) guarantees that, in the first period, the quantity of units transferred from the manufacturer to the warehouse cannot exceed the warehouse capacity. Constraint (12) guarantees that the total quantity of products entering the warehouse in each period and products remaining from the previous period cannot exceed the warehouse pre-specified capacity.

\section{FIFO constraint}

The FIFO (First In - First Out) policy is best for perishable products where inventory has a short shelf lifetime. This is because it prioritizes the oldest products that will maximize the use of inventory before products perishes in order to prevent expiration of products and to minimize costs arising from those expired products.

$$
\begin{gathered}
I_{a t}=\sum_{m} Q M W_{m t}-\sum_{r} Q W R_{r t}, \quad t=1, a=1 \\
I_{a t}=\sum_{m} Q M W_{m t}-\max \left\{\left(\sum_{1}^{t} \sum_{r} D_{r t}-\sum_{1}^{t-1} \sum_{r} Q W R_{r t}\right)-\sum_{a=1}^{S-1} I_{a, t-1}, 0\right\}, t=2, \ldots, T, a=1 \\
I_{a t}=\max \left\{I_{a-1, t-1}-\max \left\{\left(\sum_{1}^{t} \sum_{r} D_{r t}-\sum_{1}^{t-1} \sum_{r} Q W R_{r t}\right)-\sum_{j=a}^{S-1} I_{j, t-1}, 0\right\}, 0\right\}, t=2, \ldots, T, a=2, \ldots, S
\end{gathered}
$$


Constraints (13 - 15) calculate the inventory remaining in the warehouse at the end of each period. They guarantee that the units are handled based on the FIFO inventory policy. The age-distribution of the units in stock is monitored, under a FIFO inventory policy, where the oldest inventory, or inventory of the highest age, will be used first to fulfil demand, then the inventory of the intermediate age, and finally the demand is fulfilled by the inventory of the freshest units, or inventory of the lowest age.

\section{Warehouse inventory balance constraint}

$$
\sum_{m} Q M W_{m t}+\sum_{a=1}^{t-1} I_{a, t-1}=\sum_{c} Q W R_{r t}+\sum_{a=1}^{t} I_{a t}+\operatorname{Iexp}_{t} \quad, \quad \forall m, r
$$

Constraints (16) guarantees the warehouse inventory balance equation. The quantity of units transferred from the manufacturer to the warehouse and the remaining inventory in the previous period equals to the quantity of units transferred from the warehouse to the retailer and the inventory at this period and the expired ones.

\section{Expired inventory constraint}

$$
\begin{gathered}
\operatorname{Iexp}_{t}=0 \quad, 1 \leq t \leq S \\
\operatorname{Iexp}_{t}=\max \left(I_{a, t-1}-\left(\sum_{r} \sum_{1}^{t} D_{r t}-\sum_{r} \sum_{1}^{t-1} Q w r_{r t}\right), 0\right) \quad, \quad t>S, a=S
\end{gathered}
$$

Constraints (17) and (18) calculate the expired inventory. Constraint (17) guarantees that no expired inventory before reaching the shelf-lifetime. The expired inventory could only appear after reaching the shelf-lifetime as shown in constraint (18).

The environmental impact is minimized through preventing expiration of products and adopting the FIFO inventory policy. Prevention of expiration of products can be guaranteed by producing the sufficient quantity from the manufacturer to the warehouse according to the retailers' demands and withdrawing from the old demand (FIFO) in case of storing some quantities for the next periods. Preventing expiration of productions is important in saving the environment. Subsequently, lots of energy and resources can be conserved in the processes, i.e. material, production, and transportation ....etc.

It is valuable to mention that; the expiration cost is calculated from equation (8). This equation represents the environmental impact which is included in the objective function mentioned in equation (1).

\section{Decision variables constraints}

$$
\begin{array}{cl}
Q m w_{m t}, \quad Q w r_{r t}, \quad I_{a t}, \quad \operatorname{Iexp} p_{t} \geq 0, & \forall m, r, a, t \\
X_{m} \in\{0,1\} & , \quad \forall m
\end{array}
$$

Finally, constraint (19) ensures that, the quantities should not take negative values. While, constraint (20) ensures that $\mathrm{X}_{m}$ is binary.

\section{Model Verification}

The model has been designed, implemented in two stages to simplify verification process.

\subsection{Verification inputs}

In the first stage, the mathematical model is tested for the design of supply chain that comprises six planning intervals, single product, one potential manufacturer, one potential warehouse and one retailer. The shelf-lifetime is assumed to be three periods. The supply chain network for the first stage is illustrated in Figure 3. The values of the demand of the retailer in the six periods are assumed to be 10000,12000,14000,13000, 12000 and 11000 units respectively and the capacity of manufacturer equals to 12000 units per period while the warehouse capacity is 25000 units per period. The assumed parameters are shown in Table 2. 


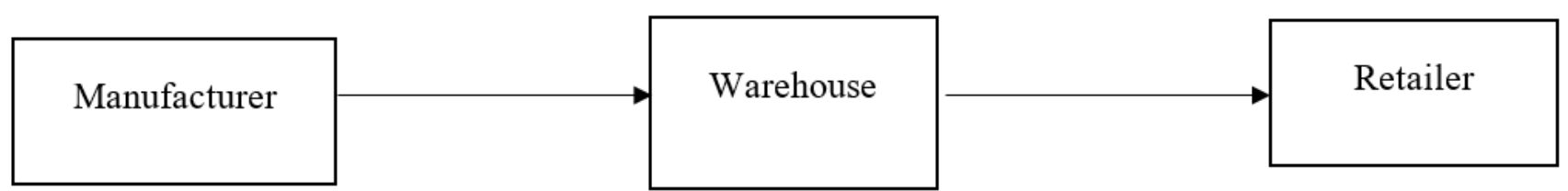

Fig 3. The supply chain network for the first stage

Table 2. The assumed parameters used in model validation in the first stage

\begin{tabular}{llll}
\hline Parameter & Value $(\$)$ & Parameter & Value \\
\hline $\operatorname{Pr}(\$)$ & 100 & SC $(\$)$ & 5 \\
$\mathrm{DMW}_{1}(\mathrm{Km})$ & 500 & MC $(\$)$ & 10 \\
$\mathrm{DWR}_{1}(\mathrm{Km})$ & 400 & PC $(\$)$ & 10 \\
TC $(\$)$ & 0.02 & FC $(\$)$ & 4,000 \\
IHC $(\$)$ & 3 & EC $(\$)$ & 10 \\
\hline
\end{tabular}

In the second stage, the mathematical model is tested for the design of supply chain that comprises three manufacturers, one warehouse and three retailers. The shelf-lifetime is assumed to be three periods. The supply chain network for this stage is illustrated in Figure 4. The values of the demand of each retailer in the six periods are assumed to be 4000, 6000, 8000, 7000, 5000 and 6000 units respectively and the capacity of each manufacturer equals to 6000 unit per period while the warehouse capacity is 25000 units per period, while other parameters used are shown in Table 3.

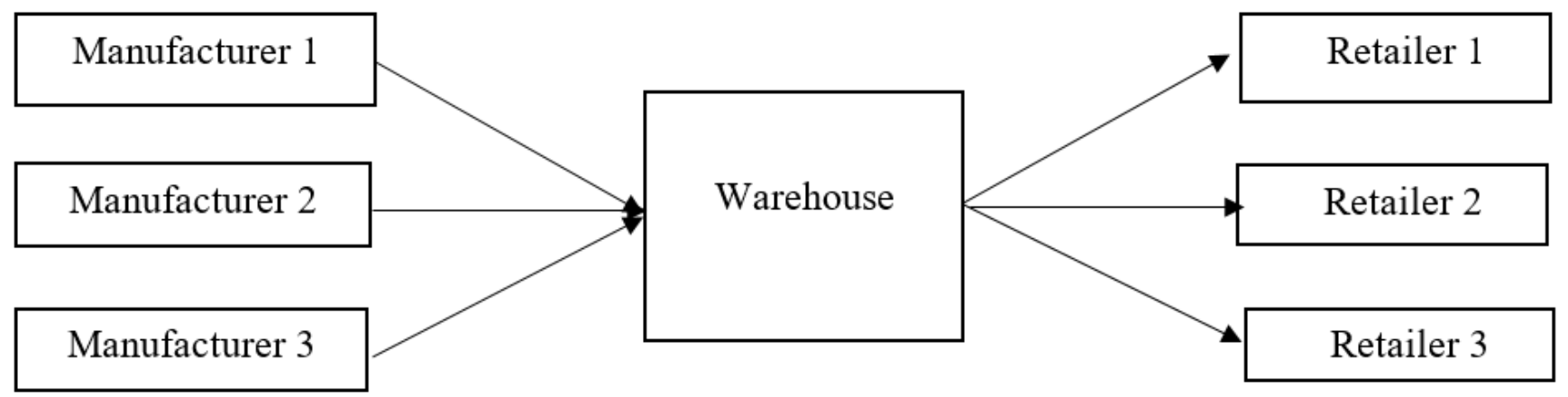

Fig 4. The optimal supply chain network for the second stage

Table 3. The assumed parameters for model verification in the second stage

\begin{tabular}{|c|c|c|c|}
\hline Parameter & Value & Parameter & Value \\
\hline $\mathrm{DMW}_{1}(\mathrm{Km})$ & 200 & $\mathrm{DWR}_{1}(\mathrm{Km})$ & 200 \\
\hline $\mathrm{DMW}_{2}(\mathrm{Km})$ & 300 & $\mathrm{DWR}_{2}(\mathrm{Km})$ & 250 \\
\hline $\mathrm{DMW}_{3}(\mathrm{Km})$ & 400 & $\mathrm{DMR}_{3}(\mathrm{Km})$ & 300 \\
\hline $\operatorname{PR}(\$)$ & 100 & $(\$)$ & 0.02 \\
\hline $\mathrm{FC}(\$)$ & 4000 & $(\$)$ & 3 \\
\hline $\mathrm{PC}(\$)$ & 10 & $(\$)$ & 10 \\
\hline $\mathrm{MC}(\$)$ & 10 & $\mathrm{SC}(\$)$ & 5 \\
\hline
\end{tabular}




\subsection{Verification Results}

\subsubsection{Results of the first stage}

Tables 4 and 5 show the results of implementing the first stage developed model. The values of the demand of the retailer in the six periods are assumed to be $10000,12000,14000,13000,12000$ and 11000 units respectively. The pre-specified capacity of the manufacturer in each period is 12,000 units. Referring to the manufacturer capacity constraint, in equation (10), the number of units transferred from the manufacturer to the warehouse in each period cannot exceed the pre-specified capacity of the manufacturer in this period, which is 12,000 units in this case. It can be observed that in the third and the fourth periods, the demand of the retailer exceeds the pre-specified capacity of the manufacturer $(14,000$ and $13,000>12,000)$. In order to maximize the expected profit in this case, the following steps are ensured by the proposed model:

- In the first period, the demand of the retailer is 10,000 units. Consequently, during the first period, the full capacity of the manufacturer (12,000 units) will be transferred from the manufacturer to the warehouse and the retailer's demand will be satisfied with 10,000 units and the rest (2,000 units) will be stored to be used in the second period. Therefore, the inventory of age 1 at the end of the first period equals 2,000 units $\left(I_{11}=2,000\right)$.

- In the second period, the demand of the retailer is 12,000 units. A quantity of 12,000 units will be transferred from the manufacturer to the warehouse and the retailer's demand will be fulfilled with 12,000 units, following the FIFO inventory policy, firstly by the 2,000 units stored from the previous period (period 1) and then with 10,000 out the 12,000 new units got in the second period. A new quantity of 2,000 units will be stored from the second period to be used in the third period. Therefore, the inventory of age 1 at the end of the second period equals 2,000 units $\left(I_{12}=2,000\right)$.

- In the third period, the demand of the retailer is 14,000 units, which exceeds the pre-specified capacity of the manufacturer, which is 12,000 units. A quantity of 12,000 units will be transferred from the manufacturer to the warehouse and the retailer's demand will be fulfilled with all the 14,000 units by those new 12,000 units and the 2,000 units stored from the second period. Hence, no inventory will be there at the end of the third period.

- In the fourth period, the demand of the retailer is 13,000 units. The available full capacity of the manufacturer $(12,000$ units) will be transferred from the manufacturer to the warehouse and the retailer's demand will be satisfied with only 12,000 units. Hence, there will be a shortage quantity of 1,000 units.

- In the fifth period, the demand of the retailer id 12,000. A quantity of 12,000 units will be transferred from the manufacturer to the warehouse, the retailer's demand will be satisfied with 12,000 units.

- In the sixth period, the demand of the retailer is 11,000 units. A quantity of 12,000 units will be transferred from the manufacturer to the warehouse, the retailer's demand will be satisfied with 12,000, which are 11,000 units demanded in the sixth period and 1,000 units backlogged from the fourth period, that were considered as shortage quantities in the fourth period.

- It can be noticed that the expired inventory is prevented in all the periods in all demand scenarios $\left(\operatorname{Iexp}_{t}=0\right)$.

Table 4. Results of the developed model using Microsoft Excel

\begin{tabular}{llll}
\hline Decision variable & Value & Decision variable & Value \\
\hline QMW $_{11}$ & 12,000 & QWR $_{11}$ & 10,000 \\
QMW $_{12}$ & 12,000 & QWR $_{12}$ & 12,000 \\
QMW $_{13}$ & 12,000 & QWR $_{13}$ & 12,000 \\
QMW $_{14}$ & 12,000 & QWR $_{14}$ & 12,000 \\
QMW $_{15}$ & 12,000 & QWR $_{15}$ & 12,000 \\
QMW & 12,000 & QWR $_{16}$ & 12,000 \\
\hline Profit & & & $\$ 4,438,000$ \\
\hline
\end{tabular}

Table 5. Inventory plan of the first stage

\begin{tabular}{llllll}
\hline $\mathrm{I}_{11}$ & 2,000 & & & & \\
$\mathrm{I}_{12}$ & 2,000 & $\mathrm{I}_{22}$ & 0 & $\mathrm{I} 33$ & 0 \\
$\mathrm{I}_{13}$ & 0 & $\mathrm{I}_{23}$ & 0 & $\mathrm{I} 34$ & 0 \\
$\mathrm{I}_{14}$ & 0 & $\mathrm{I}_{24}$ & 0 & $\mathrm{I} 35$ & 0 \\
$\mathrm{I}_{15}$ & 0 & $\mathrm{I}_{25}$ & 0 & $\mathrm{I} 36$ & 0 \\
$\mathrm{I}_{16}$ & 0 & $\mathrm{I}_{26}$ & 0 & & \\
\hline
\end{tabular}




\subsubsection{Results of the second stage}

Results of the developed mathematical model in designing the perishable supply chain network in second stage are shown in Table 6.

It can be shown from the results that the developed model is working efficiently, capable of operating under the required conditions and constraints and gives reasonable results. The model is also effective, as it achieves its goal of maximizing the profit. The model enables storing in optimal behaviour and prevents the expiration of products, where there will be a positive impact on the environment.

Table 6. Results of the developed mathematical model in designing the perishable supply chain network in the second stage (In thousands)

\begin{tabular}{|c|c|c|c|c|c|c|c|c|c|c|c|c|c|c|}
\hline \multirow{2}{*}{$\mathrm{t}$} & \multicolumn{3}{|c|}{ Parameter } & \multicolumn{11}{|c|}{ Decision variables } \\
\hline & \multicolumn{3}{|c|}{$\mathrm{D}_{r t}$} & \multicolumn{3}{|c|}{$\mathrm{QMW}_{m t}$} & \multicolumn{3}{|c|}{ QWRrt } & \multicolumn{3}{|c|}{$\mathrm{I}_{a t}$} & \multirow{2}{*}{$\operatorname{Iexp}_{t}$} & \multirow{2}{*}{ Profit (\$) } \\
\hline $\mathrm{t}$ & $\mathrm{r} 1$ & $\mathrm{r} 2$ & r3 & $\mathrm{m} 1$ & $\mathrm{~m} 2$ & $\mathrm{~m} 3$ & r1 & $\mathrm{r} 2$ & r3 & a1 & $\mathrm{a} 2$ & a3 & & \\
\hline 1 & 4 & 4 & 4 & 6 & 6 & 6 & 4 & 4 & 4 & 6 & & & 0 & \multirow{6}{*}{7,389} \\
\hline 2 & 6 & 6 & 6 & 6 & 6 & 6 & 6 & 6 & 6 & 6 & 0 & & 0 & \\
\hline 3 & 8 & 8 & 8 & 6 & 6 & 6 & 8 & 8 & 8 & 0 & 0 & 0 & 0 & \\
\hline 4 & 7 & 7 & 7 & 6 & 6 & 6 & 7 & 7 & 4 & 0 & 0 & 0 & 0 & \\
\hline 5 & 5 & 5 & 5 & 6 & 6 & 6 & 5 & 5 & 8 & 0 & 0 & 0 & 0 & \\
\hline 6 & 6 & 6 & 6 & 6 & 6 & 6 & 6 & 6 & 6 & 0 & 0 & 0 & 0 & \\
\hline
\end{tabular}

\section{Results and Discussion}

This set of experiments is concerned with studying the effect of change in demands on the establishment of manufacturers. The effect of different demand scenarios will be studied on the manufacturers' establishment. The maximum allowable capacities of each manufacturer in each period are shown in Table 7. The demand scenarios are shown in Supplementary table 1. The following demand scenarios have been analysed, in order to check whether the model enables the establishment of the manufacturer in optimal behaviour. Supplementary table 2 and Figure 5 show the model behaviour on studying different demand scenarios on the manufacturers' establishment.

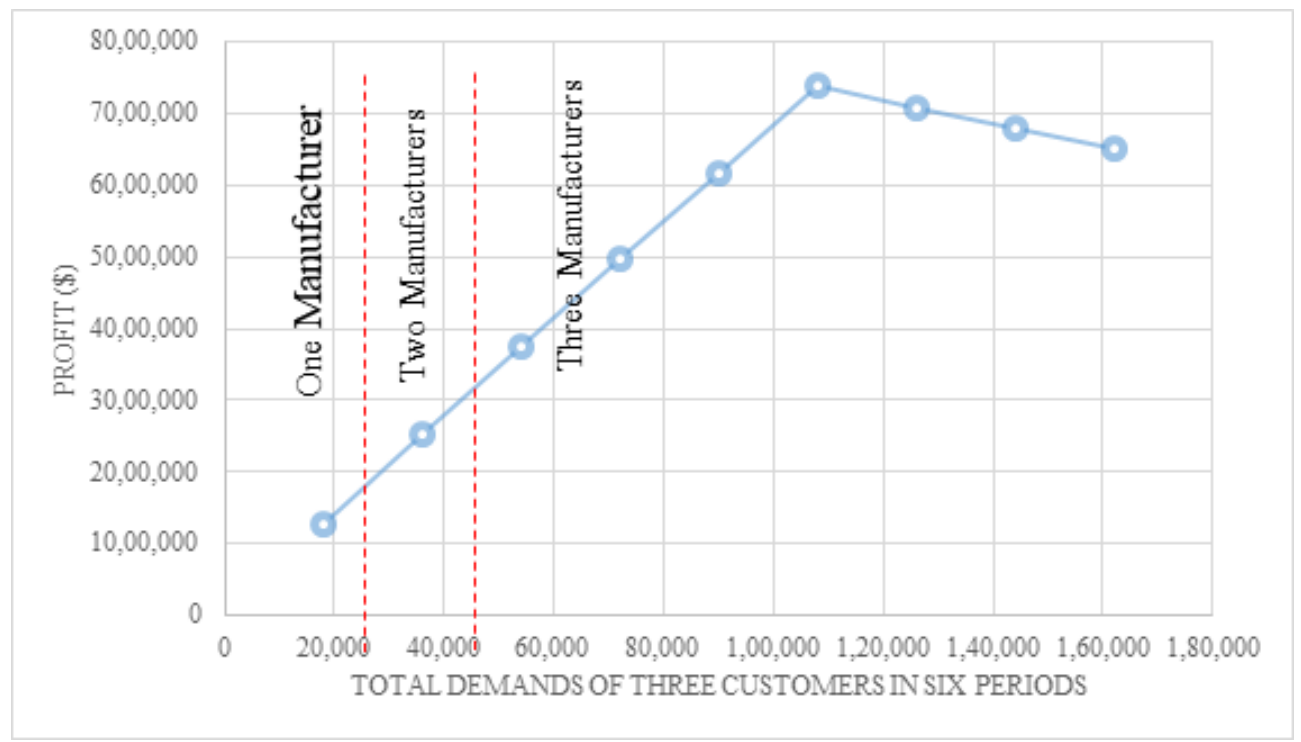

Fig 5. Effect of change in demands on the no. of manufacturers 
Table 7. The maximum allowable capacities of each manufacturer in each period (In thousands)

\begin{tabular}{|c|c|c|c|c|}
\hline \multirow[b]{2}{*}{$\mathrm{t}$} & \multicolumn{3}{|c|}{$\mathrm{CapM}_{m t}$} & \multirow{2}{*}{ Total } \\
\hline & $\mathrm{m} 1$ & $\mathrm{~m} 2$ & $\mathrm{~m} 3$ & \\
\hline 1 & 6 & 6 & 6 & 18 \\
\hline 2 & 5 & 6 & 7 & 18 \\
\hline 3 & 4 & 6 & 8 & 18 \\
\hline 4 & 3 & 6 & 9 & 18 \\
\hline 5 & 5 & 6 & 7 & 18 \\
\hline 6 & 4 & 6 & 8 & 18 \\
\hline
\end{tabular}

In scenario \#1, the total demands of the three retailers in each period are 3,000 units, a quantity of 3,000 units will be transferred from the first manufacturer to the retailer. The first manufacturer "the nearest" will be established (i.e. $X_{1}=1$ ), while there will be no need to establish the second or the third manufacturer in this case (i.e. $X_{2}$ and $X_{3}=0$ ), as the demands of the retailers can be fully satisfied by only one manufacturer.

In scenario \#2, the total demands of the three retailers in each period are 6,000 units, manufacturer 1 "the nearest manufacturer" will transfer its full capacity in each period, while the remaining units will be transferred from manufacturer 2. No units will be transferred from manufacturer 3 "the farthest". Only two manufacturers will be established (i.e. $\mathrm{X}_{1}$ and $\mathrm{X}_{2}=1$ while $\mathrm{X}_{3}=0$ ), as the demands of the retailers can be satisfied by the establishment of two manufacturers. This also happens in scenario \#3, where the network will be composed of only two manufacturers, one warehouse and three retailers.

In scenario \#4, three manufacturers will be established (i.e. $\mathrm{X}_{1}, \mathrm{X}_{2}$ and $\mathrm{X}_{3}=1$ ). The demands of each of the three retailers in each period is 18,000 units, each manufacturer (1,2 and 3) will transfer their full capacity in each period. In scenarios from \#4 to $\# 9$, the network is composed of three manufacturers, one warehouse and three retailers.

In scenario \#6, the total demands of all retailers in each period also equal 18,000 units. The total maximum full capacities of all the three manufacturers per period also equal 18,000 units. Three manufacturers will be established and a total quantity of 18,000 units will be transferred from the three manufacturers to the warehouse in each period. Subsequently, the retailers' demands will be fully satisfied by the establishment of the three manufacturers without shortage quantities.

In scenarios \#7 and \#8, the total demands of all retailers in each period also exceed the total maximum capacities of the manufacturers. It can be observed in Figure 5 that there will be an inverse relationship between the total demands of the retailers per period and the profit. The reason is that there will be shortage quantities that will have a negative impact on the profit due to the shortage costs.

It can be observed that the proposed model works perfectly in the concept of establishment of manufacturers. Manufacturing centres will be opened only if they are required, according to the demands of the retailers.

\section{Conclusion and Future Research}

In this research, a sustainable supply chain network design model has been proposed for perishable products to prevent expiration of products considering FIFO inventory policy in order to maximize the total profit of the network and minimize the environmental impact through preventing waste of expiration.

The model successfully has solved the problem of sustainable supply chain network design for perishable products considering multi-period inventory in the warehouse, in addition to considering backlog; where the unmet demand in any period can be fulfilled in the subsequent periods. It has helped in preventing expiration of products, where only needed quantities are produces without waste.

The model results have been verified through different scenarios. Expiration prevention of products led to maximizing the profit and minimizing the environmental impact.

This work can be extended in future through:

- Modifying the proposed model into a multi-product model.

- Considering the inventory of products for perishable products in retailers.

- Dealing with uncertainty in demand.

- Incorporating more objectives in the optimization.

- Adding promotions to the oldest items. 


\section{References}

1) Patidar R, Venkatesh B, Pratap S, Daultani Y. A Sustainable Vehicle Routing Problem for Indian Agri-Food Supply Chain Network Design. In: and others, editor. International Conference on Production and Operations Management Society (POMS). IEEE. 2018.

2) Dai Z, Aqlan F, Zheng X, Gao K. A location-inventory supply chain network model using two heuristic algorithms for perishable products with fuzzy constraints. Computers \& Industrial Engineering. 2018;119:338-352. Available from: https://dx.doi.org/10.1016/j.cie.2018.04.007.

3) Rashidi S, Saghaei A, Sadjadi SJ, Sadi-Nezhad S. Optimizing supply chain network design with location-inventory decisions for perishable items: A Pareto-based MOEA approach. Scientia Iranica. 2016;23(6):3025-3045. Available from: https://dx.doi.org/10.24200/sci.2016.4009.

4) Validi S, Bhattacharya A, Byrne PJ. A case analysis of a sustainable food supply chain distribution system-A multi-objective approach. International Journal of Production Economics. 2014;152:71-87. Available from: https://dx.doi.org/10.1016/j.ijpe.2014.02.003.

5) Dwivedi A, Jha A, Prajapati D, Sreenu N, Pratap S. Meta-heuristic algorithms for solving the sustainable agro-food grain supply chain network design problem. Modern Supply Chain Research and Applications. 2020;2:161-177. Available from: https://dx.doi.org/10.1108/mscra-04-2020-0007.

6) Chalmardi MK, Camacho-Vallejo JF. A bi-level programming model for sustainable supply chain network design that considers incentives for using cleaner technologies. Journal of Cleaner Production. 2019;213:1035-1050. Available from: https://dx.doi.org/10.1016/j.jclepro.2018.12.197.

7) Eskandari-Khanghahi M, Tavakkoli-Moghaddam R, Taleizadeh AA, Amin SH. Designing and optimizing a sustainable supply chain network for a blood platelet bank under uncertainty. Engineering Applications of Artificial Intelligence. 2018;71:236-250. Available from: https://dx.doi.org/10.1016/j.engappai. 2018.03.004.

8) Zahiri B, Zhuang J, Mohammadi M. Toward an integrated sustainable-resilient supply chain: A pharmaceutical case study. Transportation Research Part E: Logistics and Transportation Review. 2017;103:109-142. Available from: https://dx.doi.org/10.1016/j.tre.2017.04.009.

9) Eskandarpour M, Dejax P, Miemczyk J, Péton O. Sustainable supply chain network design: An optimization-oriented review. Omega. 2015;54:11-32. Available from: https://dx.doi.org/10.1016/j.omega.2015.01.006.

10) Mohebalizadehgashti F, Zolfagharinia H, Amin SH. Designing a green meat supply chain network: A multi-objective approach. International Journal of Production Economics. 2020;219:312-327. Available from: https://dx.doi.org/10.1016/j.ijpe.2019.07.007.

11) Varsei M, Polyakovskiy S. Sustainable supply chain network design: A case of the wine industry in Australia. Omega. 2017;66:236-247. Available from: https://dx.doi.org/10.1016/j.omega.2015.11.009.

12) Daghigh R, Jabalameli MS, Amiri AB, Pishvaee MS. A multi-objective location-inventory model for 3PL providers with sustainable considerations under uncertaint. International Journal of Industrial Engineering Computations. 2016;7(4):615-634. Available from: https://dx.doi.org/10.5267/j.ijiec.2016.3.003.

13) Babazadeh R, Razmi J, Pishvaee MS, Rabbani M. A sustainable second-generation biodiesel supply chain network design problem under risk. Omega. 2017;66:258-277. Available from: https://dx.doi.org/10.1016/j.omega.2015.12.010.

14) Rohmer SUK, Gerdessen JC, Claassen GDH. Sustainable supply chain design in the food system with dietary considerations: A multi-objective analysis. European Journal of Operational Research. 2019;273(3):1149-1164. Available from: https://dx.doi.org/10.1016/j.ejor.2018.09.006.

15) Arvan M, Tavakoli-Moghadam R, Abdollahi M. Designing a bi-objective and multi-product supply chain network for the supply of blood. Uncertain Supply Chain Management. 2015;3(1):57-68. Available from: https://dx.doi.org/10.5267/j.uscm.2014.8.004.

16) Diabat A, Jabbarzadeh A, Khosrojerdi A. A perishable product supply chain network design problem with reliability and disruption considerations. International Journal of Production Economics. 2019;212:125-138. Available from: https://dx.doi.org/10.1016/j.ijpe.2018.09.018.

17) Isaloo F, Paydar MM. Optimizing a robust bi-objective supply chain network considering environmental aspects: a case study in plastic injection industry. International Journal of Management Science and Engineering Management. 2020;15(1):26-38. Available from: https://dx.doi.org/10.1080/17509653.2019. 1592720.

18) Yakavenka V, Mallidis I, Vlachos D, Iakovou E, Eleni Z. Development of a multi-objective model for the design of sustainable supply chains: the case of perishable food products. Annals of Operations Research. 2020;294(1-2):593-621. Available from: https://dx.doi.org/10.1007/s10479-019-03434-5.

19) Tsao YC. Designing a supply chain network for deteriorating inventory under preservation effort and trade credits. International Journal of Production Research. 2016;54(13):3837-3851.

20) Jouzdani J, Fathian M, Makui A, Heydari M. Robust design and planning for a multi-mode multi-product supply network: a dairy industry case study. Operational Research. 2020;20(3):1811-1840. Available from: https://dx.doi.org/10.1007/s12351-018-0395-0.

21) Savadkoohi E, Mousazadeh M, Torabi SA. A possibilistic location-inventory model for multi-period perishable pharmaceutical supply chain network design. Chemical Engineering Research and Design. 2018;138:490-505. Available from: https://dx.doi.org/10.1016/j.cherd.2018.09.008.

22) Dagne TB, Jayaprakash J, Geremew S. Design of Supply Chain Network Model for Perishable Products with Stochastic Demand: An Optimized Model. Journal of Optimization in Industrial Engineering. 2020;13(1):29-37.

23) Guo Y, Hu F, Allaoui H, Boulaksil Y. A distributed approximation approach for solving the sustainable supply chain network design problem. International Journal of Production Research. 2019;57(11):3695-3718. Available from: https://dx.doi.org/10.1080/00207543.2018.1556412.

24) Halim I, Ang P, Adhitya A. A decision support framework and system for design of sustainable pharmaceutical supply chain network. Clean Technologies and Environmental Policy. 2019;21:431-446. Available from: https://dx.doi.org/10.1007/s10098-018-1646-8.

25) Govindan K, Jafarian A, Khodaverdi R, Devika K. Two-echelon multiple-vehicle location-routing problem with time windows for optimization of sustainable supply chain network of perishable food. International Journal of Production Economics. 2014;152:9-28. Available from: https://dx.doi.org/10. 1016/j.ijpe.2013.12.028.

26) Yun Y, Chuluunsukh A, Gen M. Sustainable Closed-Loop Supply Chain Design Problem: A Hybrid Genetic Algorithm Approach. Mathematics. 2020;8(1):84-84. Available from: https://dx.doi.org/10.3390/math8010084.

27) Sabouhi F, Pishvaee MS, Jabalameli MS. Resilient supply chain design under operational and disruption risks considering quantity discount: A case study of pharmaceutical supply chain. Computers \& Industrial Engineering. 2018;126:657-672. Available from: https://dx.doi.org/10.1016/j.cie.2018.10.001.

28) Moghaddam ST, Javadi M, Molana SMH. A reverse logistics chain mathematical model for a sustainable production system of perishable goods based on demand optimization. Journal of Industrial Engineering International. 2019;15(4):709-721. Available from: https://dx.doi.org/10.1007/s40092-018-02871.

29) Mousazadeh M, Torabi SA, Zahiri B. A robust possibilistic programming approach for pharmaceutical supply chain network design. Computers \& Chemical Engineering. 2015;82:115-128. Available from: https://dx.doi.org/10.1016/j.compchemeng.2015.06.008.

30) Zahiri B, Jula P, Tavakkoli-Moghaddam R. Design of a pharmaceutical supply chain network under uncertainty considering perishability and substitutability of products. Information Sciences. 2018;423:257-283. Available from: https://dx.doi.org/10.1016/j.ins.2017.09.046. 
31) Musavi M, Bozorgi-Amiri A. A multi-objective sustainable hub location-scheduling problem for perishable food supply chain. Computers \& Industrial Engineering. 2017;113:766-778. Available from: https://dx.doi.org/10.1016/j.cie.2017.07.039.

32) Jiang Y, Zhao Y, Dong M, Han S. Sustainable Supply Chain Network Design with Carbon Footprint Consideration: A Case Study in China. Mathematical Problems in Engineering. 2019;p. 1-19.

33) Yavari M, Zaker H. Designing a resilient-green closed loop supply chain network for perishable products by considering disruption in both supply chain and power networks. Computers \& Chemical Engineering. 2020;134. Available from: https://dx.doi.org/10.1016/j.compchemeng.2019.106680. 